\title{
Use of localized human growth hormone and testosterone injections in addition to manual therapy and exercise for lower back pain: a case series with 12-month follow-up
}

\author{
This article was published in the following Dove Press journal: \\ Journal of Pain Research \\ 23 June 2015 \\ Number of times this article has been viewed
}

\author{
Marc N Dubick' \\ Thomas H Ravin ${ }^{2}$ \\ Yvonne $\mathrm{Michel}^{3}$ \\ David C Morrisette ${ }^{4}$ \\ 'Interventional Pain Management, \\ Division of Anesthesiology, Bon \\ Secours St Francis Hospital, \\ Charleston, SC, USA; ${ }^{2}$ Musculoskeletal \\ Medicine, Val d'Isere Health Clinic, \\ Denver, CO, USA; ${ }^{3}$ Statistical \\ Consultant, Private Practice, Daniel \\ Island, SC, USA; ${ }^{4}$ Division of Physical \\ Therapy, Medical University of South \\ Carolina, SC, USA
}

\begin{abstract}
Objective: The objective of this case series was to investigate the feasibility and safety of a novel method for the management of chronic lower back pain. Injections of recombinant human growth hormone and testosterone to the painful and dysfunctional areas in individuals with chronic lower back pain were used. In addition, the participants received manual therapies and exercise addressing physical impairments such as motor control, strength, endurance, pain, and loss of movement. Pain ratings and self-rated functional outcomes were assessed.
\end{abstract}

Study design: This is a case series involving consecutive patients with chronic lower back pain who received the intervention of injections of recombinant human growth hormone and testosterone, and attended chiropractic and/or physical therapy. Outcomes were measured at 12 months from the time of injection.

Setting: A community based hospital affiliated office, and a private practice block suite.

Participants: A total of 60 consecutive patients attending a pain management practice for chronic lower back pain were recruited for the experimental treatment. Most participants were private pay.

Interventions: Participants who provided informed consent and were determined not to have radicular pain received diagnostic blocks. Those who responded favorably to the diagnostic blocks received injections of recombinant human growth hormone and testosterone in the areas treated with the blocks. Participants also received manipulation- and impairment-based exercises.

Outcome measures: Outcomes were assessed at 12 months through pain ratings with the Mankowski Pain Scale and the Oswestry Disability Index.

Results: Of the 60 patients recruited, 49 provided informed consent, and 39 completed all aspects of the study. Those patients receiving the intervention reported a significant decrease in pain ratings $(P<0.01)$ and a significant improvement in self-rated Oswestry Disability Index scores $(P<0.01)$. In addition, in the Oswestry Disability Index results, $41 \%$ of the patients demonstrated a $50 \%$ or greater change in their disability score. Of the subjects who withdrew from the study, one was due to the pain created by the injections and nine were for nonstudy factors.

Conclusion: The intervention appeared to be safe and the results provide a reasonable expectation that the intervention would be beneficial for a population of individuals with chronic nonradicular lower back pain. Due to the design of the study, causality cannot be inferred, but the results do indicate that further study of the intervention may be warranted.

Keywords: lumbar, sacroiliac joint, manual therapy, injections, pain management, rehabilitation
Correspondence: Marc N Dubick Interventional Pain Management, Bon Secours St Francis Hospital, 2097 Henry Tecklenburg Blvd, Suite 203 West, Charleston, SC 29414, USA

Tel +l 8435733444

Fax +18437694312

Email marcndubick@gmail.com 


\section{Background and significance}

The efficacy of injection therapy for low back pain (LBP) can be regarded as having mixed results and limited longterm clinical benefit. ${ }^{1,2}$ Likewise, the evidence is mixed regarding exercise and manual therapy for the management of chronic LBP (CLBP). ${ }^{3-5}$ Reviews have indicated generally similar, but mixed short-term responses for facet injections and physiotherapy treatment. ${ }^{6}$ Lumbar facet joint injection is recommended as the first line of treatment prior to lumbar facet radiofrequency denervation, with similar results obtained from both treatments. ${ }^{7,8}$

A problem in investigating CLBP is the lack of agreement of the definition of CLBP, with the definition including 12 weeks of pain, pain lasting longer than the expected healing time,, and pain lasting beyond 3 months. ${ }^{10}$ The "socioprofessional" factors and psychosocial dysfunction are also confounding factors in regard to investigating interventions for mechanical LBP. It appears that depression may hinder the long-term outcome for lumbar pain managed through radiofrequency denervation of the facet. ${ }^{11}$ Licciardone et $\mathrm{al}^{12,13}$ describe a predominance of somatic dysfunction in the lower back and pelvic girdle area in individuals with CLBP, indicating that for many, the problem may well be multifactorial and includes somatic components.

While facet and sacroiliac joint denervation have demonstrated successful moderate-duration pain relief when the joint is determined to be the source of pain, the intervention requires destruction of nervous tissue and does not directly address pathology or modulate pain from areas other than the joint. ${ }^{14}$ Clearly, delineation of new beneficial treatments for LBP, and particularly CLBP, would be welcome. A significant volume of patients with LBP are reported to present with structural pain involving tendon, ligament, and joint degeneration and dysfunction. ${ }^{15-17}$ If the etiology of the ongoing pain and dysfunction includes both movement impairments and soft tissue degenerative change, interventions to address both impairments and pathology should prove to be more beneficial than addressing one problem alone.

Exercise and manual therapy are intended to address motor control, movement impairment, and dysfunction, with any change in the soft tissues occurring through remodeling, which requires extended time and adherence to lifestyle changes and interventions. ${ }^{18-20}$ An alternative intervention that facilitates tissue remodeling would be expected to shorten and improve the rehabilitation process. Localized injections with recombinant human growth hormone (rhGH) and testosterone are conceivable candidates as treatment options for this purpose. Both are endogenous anabolic hormones that stimulate protein synthesis and have demonstrated marked benefits on early wound healing. ${ }^{21-23}$

The systemic effects of rhGH have classically been attributed to the production of its sister molecule, insulin-like growth factor (IGF)-1, in the liver. However, rhGH has also been found to stimulate protein synthesis independent of IGF-1, working locally as well as systemically. ${ }^{24-28}$ In addition, protein synthesis is facilitated by the presence of anabolic hormones. A synergistic effect of testosterone and rhGH on protein synthesis has been repeatedly demonstrated. ${ }^{25-28}$ With this potential influence on protein synthesis, the injection of rhGH and testosterone into degenerative tissue may possibly lead to the formation of new collagen and its maturation into new connective tissue at the injection site, although this mechanism could create contractures and unwanted scarring as well. It is hypothesized that this type of injection will lead to strengthened collagen and improvement in the biomechanical properties of chronically degenerated, damaged, and painful tissue, such as ligament and joint capsule. In conjunction with the injections, rehabilitation involving manual therapy and exercise would be expected to positively influence movement behavior, motor control, and remodeling of the neuromuscular system and dense connective tissue, while possibly preventing contractures, but this is highly theoretical.

The potential mechanisms for the injection to be effective include both the needling of the tissue and introduction of the rhGH and testosterone. The needling of the fibro-osseous junction during the injection of these two anabolic hormones produces an injury that possibly stimulates macrophages into action. Macrophages have been found to be a rich source of diverse growth factors that can direct repair and remodeling after injury ${ }^{29,30}$ and are thought to play an integral role in successful healing processes, including wound debridement, initiation of neovascular growth, and stimulation of fibroblast proliferation and protein synthesis. ${ }^{30-32}$ Both rhGH and testosterone may exert an effect on the macrophage as an activating factor, acting directly on receptors, independent of IGF-1. ${ }^{33,34}$ In addition, macrophages have been found to recruit stem cells to the wound area, which may possibly further stimulate the healing process. ${ }^{29}$ Further information on the stimulation of tissue healing and growth with rhGH and testosterone has been discussed elsewhere..$^{35-46}$

Based on the potential for injections to promote the regeneration of connective tissue and rehabilitation to improve function, the combination exhibits potential to lead to improved outcomes in CLBP. To investigate the feasibility and the potential for the synergistic benefit of these interventions for LBP, a case series using the novel 
treatment of rhGH and testosterone injections combined with rehabilitative therapy for CLBP patients was undertaken. The purpose of this case series is to demonstrate the feasibility of a novel injection for CLBP and that the technique can be accomplished safely. Once the protocol is determined to be safe and potentially effective, studies to investigate clinical outcomes through randomized controlled trials and to discern the mechanism of action can be conducted, for which controls for psychosocial and other variables can be instituted.

\section{Methods Study design}

The study represents a case series of sequential participants who met the inclusion criteria. The purpose of the case series was to determine the feasibility of conducting a future randomized controlled trial. This 12-month follow-up case series was undertaken in a private pain management clinic. While the participants were receiving the injections, they were also seen in community chiropractic and physical therapy clinics for rehabilitation that focused on manual therapy and stabilization/motor control exercises.

The study was approved by the Institutional Review Board of Roper St Francis Healthcare, Charleston, SC, USA. Data were monitored by a Data Collection Site Monitoring Board and Adverse Experience Reporting Committee. A board-certified, hospital-affiliated anesthesiologist/pain management physician administered the initial examinations and injections under fluoroscopy. Patients participating in the case series were also examined by and received impairmentbased manual therapy and exercise programs administered by chiropractors and/or physical therapists.

\section{Participants}

Sixty consecutive adult participants, aged 18 years or older with nonradicular CLBP were sequentially recruited as a convenience sample during the interval of June 2009 to June 2011. Inclusion and exclusion criteria are listed in Table 1. Participants were followed up at 1 month, 3 months, 6 months, and 12 months following the last injection. Following a standardized clinical examination by both the anesthesiologist/pain management physician and the chiropractors/physical therapists, a specific diagnosis of pain secondary to lumbar facet, sacroiliac joint, and/or ligament dysfunction was determined with local anesthetic injections performed under fluoroscopic guidance. Complete or near complete $(90 \%)$ resolution of pain was considered diagnostic for nonradicular pain and was used to determine the location for the study injections. ${ }^{47,48}$ All participating
Table I Inclusion and exclusion criteria

\section{Inclusion criteria}

Age 18 years or older

Lower back pain without radicular symptoms

Symptoms subjectively relieved by $90 \%$ or greater with fluoroscopically guided diagnostic injections

Willingness to self-pay for the injection therapy

Symptoms of 6 months or longer duration

Exclusion criteria

Bowel or bladder dysfunction related to LBP

Current vertebral/pelvic girdle fracture

Failure to demonstrate significant relief with diagnostic injection

Rheumatic disease

Active or recurrent carcinoma

History of prostatic carcinoma

Objective neurological deficit/radicular signs (myotome weakness,

dermatome sensory loss, loss of deep tendon reflex, positive SLR 2 /PKB

Slump test

Pregnancy

Notes: aSLR was considered positive if less than $40^{\circ}$ with greatest symptoms in the lower extremity; ${ }^{\circ}$ PKB considered positive if L3 or L4 dermatomal symptoms reproduced, with the worst symptoms reported in the lower extremity. Slump test considered positive if LE symptoms were reproduced with neck flexion during slump sitting/knee extension/ankle dorsiflexion, and LE was relieved to any degree with neck extension.

Abbreviations: LBP, low back pain; SLR, straight leg raise; PKB, prone knee-bend; LE, lower extremity.

patients had a negative straight leg raise, prone knee-bend test, and Slump test for radicular pain reproduction. Three participants presented with postoperative pain syndrome following fusion surgery. An additional six patients had lumbar surgery without fusion, without resolution of symptoms. Participants had received a range of management strategies including trigger point, sacroiliac joint, and lumbar facet injections, radiofrequency facet denervation, pharmacological pain management, and chiropractic and physical therapy. The interventions were not consistent across participants. Participant demographics are listed in Table 2.

\section{Interventions}

Each participant received rhGH (Sandoz rhGH; Sandoz International, Holzkirchen, Germany; $1 \mathrm{mg} / 10 \mathrm{cc}$ volume), testosterone (12.5 mg for females, $25 \mathrm{mg}$ for males, per $10 \mathrm{cc}$ volume), $5 \mathrm{cc}$ of $1 \%$ preservative-free procaine, and $0.9 \% \mathrm{NaCl}$ to a total volume of $10 \mathrm{cc}$ with injections performed at the fibro-osseous junction of symptomatic areas (ligament, tendon, and capsule) under fluoroscopic guidance at 2-4-week intervals, and they averaged four to five injections in total. Approximately three $10 \mathrm{cc}$ syringes were administered at each injection visit. An individualized rehabilitation program, including joint manipulation and exercise therapy, was designed for each participant by the participating chiropractors and physical therapists (Table 3 ). 
Table 2 Demographics for participants beginning the study $(n=39)$

\begin{tabular}{lllll}
\hline Variable & Mean & $\begin{array}{l}\text { Standard } \\
\text { deviation }\end{array}$ & Minimum & Maximum \\
\hline Age (year) & 58 & II.4 & $3 \mathrm{I}$ & 82 \\
BMI & 25.7 & 5.3 & 18.4 & 46.5 \\
$\begin{array}{l}\text { Symptom (duration } \\
\text { in months) }\end{array}$ & 105 & $\mathrm{II}$ & 6 & 360 \\
$\begin{array}{l}\text { Other demographic } \\
\text { attributes }\end{array}$ & Number of participants & \\
\hline
\end{tabular}

\begin{tabular}{|c|c|}
\hline Gender & \\
\hline Female & 23 \\
\hline Male & 16 \\
\hline Race & \\
\hline Caucasian & 38 \\
\hline Hispanic & I \\
\hline Pain location & \\
\hline Back and leg & 31 \\
\hline Back only & 8 \\
\hline Education & \\
\hline High school & 7 \\
\hline College & 15 \\
\hline Graduate school & 12 \\
\hline Did not complete high school & I \\
\hline Missing & 4 \\
\hline Duration of symptoms & \\
\hline$<$ I year & 5 \\
\hline$>$ I year & 34 \\
\hline Pain consistency & \\
\hline Constant pain & 14 \\
\hline Intermittent pain & 25 \\
\hline Health status & \\
\hline $\begin{array}{l}\text { Healthy (currently not treated } \\
\text { for a medical condition) }\end{array}$ & 37 \\
\hline Chronic illness (currently & 2 \\
\hline treated for a chronic & \\
\hline condition) & \\
\hline Financial & \\
\hline Self-pay & 36 \\
\hline Private insurance & 2 \\
\hline Worker's compensation & I \\
\hline Occupation & \\
\hline Retired & II \\
\hline Office work & 9 \\
\hline Professional & 10 \\
\hline Manual laborer & 3 \\
\hline Retail & I \\
\hline Homemaker & I \\
\hline Artist & I \\
\hline Police officer & 1 \\
\hline Driver & 1 \\
\hline Walking tour guide & I \\
\hline
\end{tabular}

Notes: Means, standard deviations, and ranges reported for participant age, BMI, and duration of symptoms. Other demographic data are reported by the number of participants with a specific characteristic. While $3 \mathrm{I}$ of the individuals who signed a consent form indicated that they had pain in the leg, none of the participants had neurological signs.

Abbreviation: BMI, body mass index.

After the injection therapy was completed, participants were followed for 12 months. The participants attended therapy until discharged with a home exercise program. No attempt
Table 3 Interventions used with rehabilitation and manual therapy

\section{Manual therapy}

Lumbar and pelvic girdle with activator by chiropractor

Muscle energy technique/neuromuscular mobilization

High velocity, low amplitude thrust to pelvic girdle, hips, and lumbar

regions to areas tested with restricted motion

Graded mobilization to the lumbar region, pelvic girdle, and lower

extremities to areas tested with restricted motion

Exercises and progression

Isometric abdominal and pelvic floor exercise

Multifidus exercise with hip extension in quadruped

Plank isometric holds: prone; side lying

Upper extremity- and lower extremity-resisted exercise with abdominal bracing upon demonstrating trunk control

Endurance exercise: walking; treadmill; stationary bicycle; elliptical

trainer

Balance in standing and functional activities using stabilization principles

was made to discern if the participants continued to exercise after discharge from therapy.

\section{Outcome measures}

The primary outcomes were determined by the patient's pain rating from 0 to 10 (Mankowski Pain Scale [MPS]) and the Oswestry Disability Index (ODI). The MPS is a $0-10$ pain rating scale that links verbal descriptors of the intensity of the symptoms to a numerical value. The MPS has been shown to be a valid and reliable tool for pain measurement, as compared to the Faces Scale, the Visual Analog Scale, and the Numeric Rating Scale. ${ }^{49}$ The minimal clinically important difference for the change score has not been determined, but it has reported as two points for the Numeric Rating Scale.

The ODI is a condition-specific self-rated disability tool. The minimal clinically important difference for the ODI has been reported to be between 6 and 14 points..$^{50-54}$ In addition, a $50 \%$ change in the ODI has been described as a rigorous outcome measure regarding $\mathrm{LBP} .{ }^{55}$ As a secondary outcome, participants reported overall percent change in presenting symptoms. ${ }^{27,56}$ In addition, testosterone levels (total testosterone) and HGH levels (measured as IGF-1) were measured at study intake in order to determine if a correlation exists with the baseline blood levels and the change in outcome measurement scores.

\section{Analysis}

Due to the lack of significant skewness and the absence of outlier/extreme values in the frequency distributions of the outcome variables, parametric means testing was utilized to determine the statistical significance of changes from study entry to 12-month follow-up. Pearson's correlation coefficient $R^{2}$ was used to test correlations between entry blood level 
Table 4 Change scores in outcome measures and statistical significance

\begin{tabular}{|c|c|c|c|c|c|c|}
\hline Outcome measure & $\begin{array}{l}\text { Timing of } \\
\text { Measurement }\end{array}$ & Mean & $\begin{array}{l}\text { Standard } \\
\text { deviation }\end{array}$ & Minimum & Maximum & $t, d f, P$ \\
\hline Oswestry Disability Index score & Pre & 46.7 & 13.7 & 18 & 68 & \\
\hline \multirow[t]{2}{*}{$(0 \%-100 \%)$} & Post & 24.5 & 17.2 & 0 & 54 & \\
\hline & Change & 22.2 & 15.0 & -2 & 58 & $8.1,29,<0.01$ \\
\hline \multirow[t]{3}{*}{ Mankowski Pain Scale (0-10) } & Pre & 6 & 2 & 3 & 10 & \\
\hline & Post & 3 & 2 & 0 & 8 & \\
\hline & Change & 3 & 2 & -1 & 6 & $7.5,29,<0.01$ \\
\hline $\begin{array}{l}\text { Self-rated improvement rating } \\
(0 \%-100 \%)\end{array}$ & & 74 & 23 & 30 & 100 & $|8.2,32,<0.0|$ \\
\hline
\end{tabular}

Notes: Mean pre- and postintervention scores at 12-month follow-up, standard deviations, and range of scores for the Oswestry Disability Index, Mankowski Pain Scale, and self-rated improvement. The Oswestry Disability Index and Mankowski Pain Scale scores improved at a significant level. Significance was tested through a paired $t$-test between baseline and the 12-month assessment. $N=39$ participants that completed the 12-month assessment.

Abbreviation: $d f$, degrees of freedom; $t, t$ test; $P, P$ value.

IGF-1 and testosterone with the three outcome variables at 12-month follow-up.

\section{Results}

Out of all recruited patients, eleven elected to not enter the treatment program. Of the remaining 49 qualified participants, all provided informed consent to enter the study. All phases of the study including the 12-month follow-up were completed by 39 of the 49 qualified patients (80\%). Of the ten who did not complete the study, three were noncompliant with the treatment protocol, six had surgical procedures, and one felt the injections were too painful (Table 1). Of the surgical procedures, three were not related to the back pain problem. A laminectomy and two fusion procedures were performed on the other three participants. At the 12-month follow-up, statistically significant mean decreases in pain severity (change of 3 points) and disability (change of 22.2 points) were found (Table 4). Within the ODI results, $41 \%$ of the participants reported a greater than $50 \%$ improvement. There was also a statistically significant improvement in the participants' reporting of symptoms, with an overall selfreported improvement of $74 \%$, including $92 \%$ reporting a $50 \%$ or greater improvement $(P<0.001)$.

There were no significant correlations between study entry IGF-1 or testosterone levels and changes in the three outcome variables at 12 -month follow-up $\left(R^{2}\right.$ linear $\left.\leq 0.01\right)$. While one participant dropped out of the study due to the pain associated with the injections, no other adverse reactions related to the study were reported during the course of the treatment or at the follow-up sessions. Nonstudy-related medical conditions (Figure 1) led to five individuals dropping out of the study.

\section{Discussion}

Participant outcomes demonstrate a potential for rhGH and testosterone injections in conjunction with manual therapy and exercise to play a role in improving function and relieving pain related to CLBP. This finding occurred in a group of patients where previous heterogeneous interventions, including trigger point, sacroiliac joint, and lumbar facet injections had produced suboptimal results. The case series results were achieved using a novel injection therapy along with impairment guided exercise and manipulation (Table 3). Three of the participants who started the study were dropped out due to the need for surgical intervention for their back pain: one who had a failed previous fusion; one who suffered an acute lumbar herniation and underwent a lumbar discectomy; and one who underwent lumbar fusion surgery. These individuals' data are not included in the outcomes.

A recent randomized controlled trial comparing facet steroid injections with radiofrequency denervation ${ }^{8}$ reported on two groups of patients with CLBP who received either facet injection or radiofrequency denervation. At a 6-month time point, the mean ODI for the injection group and the radiofrequency denervation group were found to be similar. Lilius et $a l^{57}$ reported no difference in the outcome between placebo and steroid facet injections. In this case series, the magnitude of the change in the ODI scores was much larger than that found for steroid injections or denervation. In addition, this case series emphasized the combination of injections with rehabilitation that was based on each participant's impairments.

Manual therapy has conflicting evidence for the management of LBP, but it does appear to be somewhat effective for acute LBP. ${ }^{58,59} \mathrm{~A}$ recent review reported that there is no clear evidence to the benefit of manipulation versus exercise for the management of CLBP. ${ }^{60}$ The present case series examined the participant outcomes with intervention with a combination of a novel injection therapy, manual therapy, and exercise. The nature of the case series does 


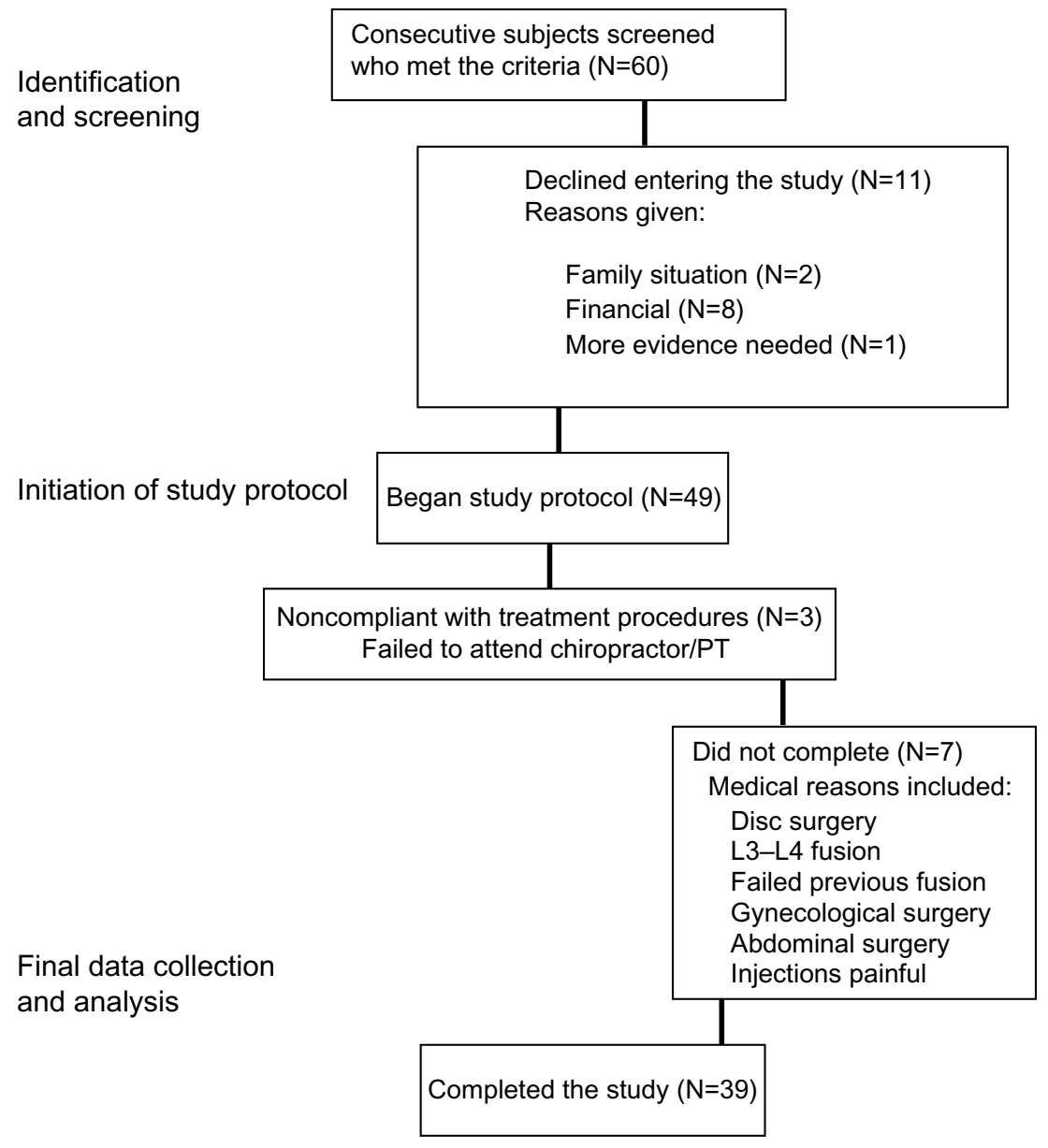

Figure I Study participation flowchart.

Note: Participants not completing the study had medical problems precluding further participation in the study or they did not follow through with rehabilitation. Abbreviation: PT, physical therapy.

not allow for any analysis of the interaction between interventions, or the specific role any of the interventions played in influencing the results. The results do support the development of future randomized controlled trials that are designed to examine these factors and others that may influence the outcomes.

\section{Limitations}

Psychosocial variables were not measured nor analyzed in this case series. While it is recognized that psychosocial variables play a major role in many individuals with CLBP, we felt that it was not possible to control for these variables in a case series of this nature. The chief purpose of this case series was to demonstrate the safety for the use of rhGH and testosterone for what was determined to be mechanical LBP.

One subject dropped out of the study due to the pain created by the injections, and no medical adverse responses were reported. Participants were told that they would be sore and that they may have increased pain for a few days following the injections, and all but one appeared to be accepting of this.

While all participants had failed to improve with previous management strategies, including various injections and surgery for some of the participants, it can still be argued that impairment-based rehabilitation rather than the injections may have had a major influence on the outcomes. Due to the nature of this case series, it is not possible to assign cause and effect to any of interventions offered. The fact that all but one of the participants completing the study reported consistent or intermittent pain for greater than 1 year prior to the intervention, and that one participant reported pain for greater than 6 months, arouses suspicion that a possible interaction between the injections and rehabilitation is of benefit, but this is unknown at this time and needs to be investigated in future studies. Only 14 (36\%) participants reported continuous pain with 25 (64\%) of the subjects reporting intermittent, yet chronic pain. It is possible that the timing of the measurement could influence the results if a patient were having a "good" 
phase of the disorder. When completing the ODI, the participants rated their function over the past week, which should help resolve this issue to some degree.

\section{Conclusion}

In summary, the combination of rhGH and testosterone injections in conjunction with rehabilitative therapy consisting of joint manipulation and exercise therapy may hold promise for a number of patients with CLBP, helping a greater number of individuals than injections, manual therapy, or exercise alone. We currently hypothesize that the injection therapy leads to the stimulation of collagen formation resulting in strengthening of the ligaments and other dense connective tissues. The remodeling of these tissues may be a causative factor leading to long-term benefits with this treatment.

This case series has demonstrated that this line of investigation is safe, with $80 \%$ of the participants completing the study, and only one dropped out due to the injection procedure, which was due to local pain during the procedure. This form of treatment has demonstrated that it has potential to help what may be a large subgroup of patients with CLBP who have no satisfactory treatment options to recommend. To our knowledge, this is the first study using localized rhGH and testosterone injection therapy in patients with CLBP and demonstrates the potential benefits in a long-term continuation. The results of this case series support the development of randomized controlled trials comparing the use of placebo injections versus rhGH and testosterone injection therapy, with and without impairment-specific rehabilitation.

\section{Disclosure}

The authors report no conflicts of interest in this work.

\section{References}

1. Pinto RZ, Maher CG, Ferreira ML, et al. Epidural corticosteroid injections in the management of sciatica: a systematic review and meta-analysis. Ann Intern Med. 2012;157(12):865-877.

2. Staal JB, de Bie RA, de Vet HC, Hildebrandt J, Nelemans P. Injection therapy for subacute and chronic low back pain: an updated Cochrane review. Spine (Phila Pa 1976). 2009;34(1):49-59.

3. Assendelft WJ, Morton SC, Yu EI, Suttorp MJ, Shekelle PG. Spinal manipulative therapy for low back pain. Cochrane Database Syst Rev. 2004;(1):CD000447.

4. Goodman DM, Burke AE, Livingston EH. JAMA patient page. Low back pain. JAMA. 2013;309(16):1738.

5. Kent $\mathrm{P}$, Mjøsund HL, Petersen DH. Does targeting manual therapy and/ or exercise improve patient outcomes in nonspecific low back pain? A systematic review. BMC Med. 2010;8:22.

6. Chambers H. Physiotherapy and lumbar facet joint injections as a combination treatment for chronic low back pain. A narrative review of lumbar facet joint injections, lumbar spinal mobilizations, soft tissue massage and lower back mobility exercises. Musculoskeletal Care. 2013;11(2):106-120.
7. Civelek E, Cansever T, Kabatas S, et al. Comparison of effectiveness of facet joint injection and radiofrequency denervation in chronic low back pain. Turk Neurosurg. 2012;22(2):200-206.

8. Lakemeier S, Lind M, Schultz W, et al. A comparison of intraarticular lumbar facet joint steroid injections and lumbar facet joint radiofrequency denervation in the treatment of low back pain: a randomized, controlled, double-blind trial. Anesth Analg. 2013;117(1):228-235.

9. Andersson GB. Epidemiological features of chronic low-back pain. Lancet. 1999;354(9178):581-585.

10. Rozenberg S. [Chronic low back pain: definition and treatment]. Rev Prat. 2008;58(3):265-272. French.

11. Streitberger K, Müller T, Eichenberger U, Trelle S, Curatolo M. Factors determining the success of radiofrequency denervation in lumbar facet joint pain: a prospective study. Eur Spine J. 2011;20(12): 2160-2165.

12. Licciardone JC, Kearns CM. Somatic dysfunction and its association with chronic low back pain, back-specific functioning, and general health: results from the OSTEOPATHIC Trial. J Am Osteopath Assoc. 2012;112(7):420-428

13. Licciardone JC, Kearns CM, King HH, et al. Somatic dysfunction and use of osteopathic manual treatment techniques during ambulatory medical care visits: a CONCORD-PBRN study. JAm Osteopath Assoc. 2014;114(5):344-354.

14. Joo YC, Park JY, Kim KH. Comparison of alcohol ablation with repeated thermal radiofrequency ablation in medial branch neurotomy for the treatment of recurrent thoracolumbar facet joint pain. J Anesth. 2013;27(3):390-395.

15. Dreyfuss P, Henning T, Malladi N, Goldstein B, Bogduk N. The ability of multi-site, multi-depth sacral lateral branch blocks to anesthetize the sacroiliac joint complex. Pain Med. 2009;10(4):679-688.

16. Langevin HM, Stevens-Tuttle D, Fox JR, et al. Ultrasound evidence of altered lumbar connective tissue structure in human subjects with chronic low back pain. BMC Musculoskelet Disord. 2009;10:151.

17. Marcus NJ, Shrikhande AA, McCarberg B, Gracely E. A preliminary study to determine if a muscle pain protocol can produce long-term relief in chronic back pain patients. Pain Med. 2013;14(8):1212-1221.

18. Grodzinsky AJ, Levenston ME, Jin M, Frank EH. Cartilage tissue remodeling in response to mechanical forces. Annu Rev Biomed Eng. 2000;2:691-713.

19. Kjaer M, Langberg H, Heinemeier K, et al. From mechanical loading to collagen synthesis, structural changes and function in human tendon. Scand J Med Sci Sports. 2009;19(4):500-510.

20. Langevin HM, Sherman KJ. Pathophysiological model for chronic low back pain integrating connective tissue and nervous system mechanisms. Med Hypotheses. 2007;68(1):74-80.

21. Demling RH. The role of anabolic hormones for wound healing in catabolic states. J Burns Wounds. 2005;4:e2.

22. Manson JM, Smith RJ, Wilmore DW. Growth hormone stimulates protein synthesis during hypocaloric parenteral nutrition. Role of hormonal-substrate environment. Ann Surg. 1988;208(2): 136-142.

23. Oh DM, Phillips TJ. Sex hormones and wound healing. Wounds. 2006;18(1):8-18.

24. Butler AA, Le Roith D. Control of growth by the somatropic axis: growth hormone and the insulin-like growth factors have related and independent roles. Annu Rev Physiol. 2001;63:141-164.

25. Giannoulis MG, Sonksen PH, Umpleby M, et al. The effects of growth hormone and/or testosterone in healthy elderly men: a randomized controlled trial. J Clin Endocrinol Metab. 2006;91(2):477-484.

26. Gibney J, Wolthers T, Johannsson G, Umpleby AM, Ho KK. Growth hormone and testosterone interact positively to enhance protein and energy metabolism in hypopituitary men. Am J Physiol Endocrinol Metab. 2005;289(2):E266-E271.

27. Mauras N, Rini A, Welch S, Sager B, Murphy SP. Synergistic effects of testosterone and growth hormone on protein metabolism and body composition in prepubertal boys. Metabolism. 2003;52(8): 964-969. 
28. Veldhuis JD, Keenan DM, Mielke K, Miles JM, Bowers CY. Testosterone supplementation in healthy older men drives GH and IGF-I secretion without potentiating peptidyl secretagogue efficacy. Eur J Endocrinol. 2005;153(4):577-586.

29. Lolmede K, Campana L, Vezzoli M, et al. Inflammatory and alternatively activated human macrophages attract vessel-associated stem cells, relying on separate HMGB1- and MMP-0-dependent pathways. J Leukoc Biol. 2009;85(5):779-787.

30. Steed DL. The role of growth factors in wound healing. Surg Clin North Am. 1997;77(3):575-586.

31. Eming SA, Krieg T, Davidson JM. Inflammation in wound repair: molecular and cellular mechanisms. J Invest Dermatol. 2007;127(3): 514-525.

32. Ravin T, Canteri M, Pasquarello G. Principles of Prolotherapy. Denver, CO: American Academy of Musculoskeletal Medicine; 2008.

33. Edwards CK 3rd, Ghiasuddin SM, Yunger LM, et al. In vivo administration of recombinant growth hormone or gamma interferon activities macrophages: enhanced resistance to experimental Salmonella typhimurium infection is correlated with generation of reactive oxygen intermediates. Infect Immun. 1992;60(6):2514-2521.

34. Warwick-Davies J, Lowrie DB, Cole PJ. Growth hormone is a human macrophage activating factor. Priming of human monocytes for enhanced release of H2O2. J Immunol. 1995;154(4):1909-1918.

35. Ashcroft GS, Mills SJ. Androgen receptor-mediated inhibition of cutaneous wound healing. J Clin Invest. 2002;110(5):615-624.

36. Brodsky IG, Balagopal P, Nair KS. Effects of testosterone replacement on muscle mass and muscle protein synthesis in hypogonadal men - a clinical research center study. J Clin Endocrinol Metab. 1996;81(10):3469-3475.

37. Cook JJ, Haynes KM, Werther GA. Mitogenic effects of growth hormone in cultured human fibroblasts. Evidence for action via local insulin-like growth factor I production. $J$ Clin Invest. 1988;81(1):206-212.

38. Demling R. The use of anabolic agents in catabolic states. $J$ Burns Wounds. 2007;6:e2

39. Doessing S, Heinemeier KM, Holm L, et al. Growth hormone stimulates the collagen synthesis in human tendon and skeletal muscle without affecting myofibrillar protein synthesis. $J$ Physiol. 2010;588(Pt 2):341-351.

40. Ferrando AA, Tipton KD, Doyle D, Phillips SM, Cortiella J, Wolfe RR. Testosterone injection stimulates net protein synthesis but not tissue amino acid transport. Am J Physiol. 1998;275(5 Pt 1):E864-E871.

41. Fryburg DA, Gelfand RA, Barrett EJ. Growth hormone acutely stimulates forearm muscle protein synthesis in normal humans. Am J Physiol. 1991;260(3 Pt 1):E499-E504.

42. Herndon DN, Pierre EJ, Stokes KN, Barrow RE. Growth hormone treatment for burned children. Horm Res. 1996;45 Suppl 1:29-31.

43. Kim SH, Heo EJ, Lee SW. The effect of topically applied recombinant human growth hormone on wound healing in pigs. Wounds. 2009;21(6):158-163.

44. Papadakis MA, Hamon G, Stotts N, et al. Effect of growth hormone replacement on wound healing in healthy older men. Wound Repair Regen. 1996;4(4):421-425.
45. Raschke M, Kolbeck S, Bail H, et al. Homologous growth hormone accelerates healing of segmental bone defects. Bone. 2001;29(4): 368-373.

46. Tahimic CG, Wang Y, Bikle DD. Anabolic effects of IGF-1 signaling on the skeleton. Front Endocrinol (Lausanne). 2013;4:6.

47. Falco FJ, Manchikanti L, Datta S, et al. An update of the systematic assessment of the diagnostic accuracy of lumbar facet joint nerve blocks. Pain Physician. 2012;15(6):E869-E907.

48. Falco FJ, Manchikanti L, Datta S, et al. An update of the effectiveness of therapeutic lumbar facet joint interventions. Pain Physician. 2012;15(6):E909-E953

49. Douglas ME, Randleman ML, DeLane AM, Palmer GA. Determining pain scale preference in a veteran population experiencing chronic pain. Pain Manag Nurs. 2014;15(3):625-631.

50. Cleland JA, Whitman JM, Houser JL, Wainner RS, Childs JD. Psychometric properties of selected tests in patients with lumbar spinal stenosis. Spine J. 2012;12(10):921-931.

51. Fairbank JC, Pynsent PB. The Oswestry Disability Index. Spine (Phila Pa 1976). 2000;25(22):2940-2952; discussion 2952.

52. Fritz JM, Irrgang JJ. A comparison of a modified Oswestry Low Back Pain Disability Questionnaire and the Quebec Back Pain Disability Scale. Phys Ther. 2001;81(2):776-788.

53. Frost H, Lamb SE, Stewart-Brown S. Responsiveness of a patient specific outcome measure compared with the Oswestry Disability Index v2.1 and Roland and Morris Disability Questionnaire for patients with subacute and chronic low back pain. Spine (Phila Pa 1976). 2008;33(22):2450-2457; discussion 2458.

54. Ostelo RW, Deyo RA, Stratford P, et al. Interpreting change scores for pain and functional status in low back pain: towards international consensus regarding minimal important change. Spine (Phila Pa 1976). 2008;33(1):90-94.

55. Fritz JM, Hebert J, Koppenhaver S, Parent E. Beyond minimally important change: defining a successful outcome of physical therapy for patients with low back pain. Spine (Phila Pa 1976). 2009;34(25): 2803-2809.

56. Cleland J, Gillani R, Bienen EJ, Sadosky A. Assessing dimensionality and responsiveness of outcomes measures for patients with low back pain. Pain Pract. 2011;11(1):57-69.

57. Lilius G, Laasonen EM, Myllynen P, Harilainen A, Salo L. [Lumbar facet joint syndrome. Significance of non-organic signs. A randomized placebo-controlled clinical study]. Rev Chir Orthop Reparatrice Appar Mot. 1989;75(7):493-500. French.

58. Wellington J. Noninvasive and alternative management of chronic low back pain (efficacy and outcomes). Neuromodulation. 2014;17 Suppl 2: 24-30.

59. Hidalgo B, Detrembleur C, Hall T, Mahaudens P, Nielens H. The efficacy of manual therapy and exercise for different stages of non-specific low back pain: an update of systematic reviews. J Man Manip Ther. 2014;22(2):59-74.

60. Merepeza A. Effects of spinal manipulation versus therapeutic exercise on adults with chronic low back pain: a literature review. J Can Chiropr Assoc. 2014;58(4):456-466.
Journal of Pain Research

\section{Publish your work in this journal}

The Journal of Pain Research is an international, peer-reviewed, open access, online journal that welcomes laboratory and clinical findings in the fields of pain research and the prevention and management of pain. Original research, reviews, symposium reports, hypothesis formation and commentaries are all considered for publication.
Dovepress

The manuscript management system is completely online and includes a very quick and fair peer-review system, which is all easy to use. Visit http://www.dovepress.com/testimonials.php to read real quotes from published authors. 